\title{
PENGARUH KUALITAS LAYANAN TERHADAP LOYALITAS PELANGGAN DI SPBU 34-17123 HARAPAN INDAH - BEKASI
}

\author{
Delvira Juang Utami Putri ${ }^{1}$, Vera Ramadhanty ${ }^{2}$, Fatimah Azzahra ${ }^{3}$ \\ ${ }^{1)}$ Marketing Communication / Komunikasi, The London School of Public Relation-Jakarta \\ ${ }^{2}$ Marketing Communication / Komunikasi, The London School of Public Relation-Jakarta \\ ${ }^{3}$ Marketing Communication / Komunikasi, The London School of Public Relation-Jakarta
}

Diterima 21-10-2019- 2020 / Disetujui 02-03-2020

\begin{abstract}
Business competition in this modern era is so diverse, that business people who provide products and services must be able to make every effort and effort to be able to survive in the business that is being run. Currently for product providers not only provide what products are needed and quality products, but no less important in business is how businesses can provide the best service for their customers. The Stimulus Response $(S-R)$ communication model is a human behavior (response) that can be predicted according to the stimulus to be sent. Regarding this, in this study the stimulus in question is service quality (variable X) and the intended response is customer loyalty (variable Y), this study uses quantitative research methodology. The object of this research is the gas station company 34-17123 Harapan Indah-Bekasi, customers who more than 3 times refuel four-wheeled vehicles as subjects, as well as service quality and customer loyalty as objects. The data obtained are primary data and secondary data. This study used a sample of 308 respondents from a total population count of 1,342 customers. The sampling technique used in this study is non-probability sampling with accidental sampling method. This study uses 5 test instruments using SPSS version 24 (Statistical Package for the Social Science) data processing application, namely validity, reliability, normality test using probability plot (p-plot), Anova (one-way Analysis of variance) test, simple linear regression analysis using partial test and a simple linear regression analysis test was performed. The results of this study are that the quality of service at SPBU 34-17123 Harapan Indah-Bekasi affects customer loyalty by 57.9\%, and 42.1\% is influenced by other factors. The results of this study have a significant effect on the significance level of $0.05 \%$ and the average customer agrees to be loyal to the SPBU 34-17123 Harapan Indah-Bekasi.
\end{abstract}

Keywords: Stimulus-Response, Service Quality, Customer Loyalty

\begin{abstract}
ABSTRAK
Persaingan bisnis dijaman moderen ini begitu beragam, sehingga para pelaku bisnis yang menyediakan produk serta pelayanan jasa harus dapat melakukan segala cara dan upaya untuk dapat bertahan pada bisnis yang sedang dijalankan. Saat ini bagi penyedia produk tidak hanya menyediakan produk apa yang sedang dibutuhkan dan produk berkualitas, tetapi yang tak kalah penting dalam usaha berbisnis adalah bagaimana para pelaku binis dapat memberikan layanan yang terbaik bagi pelanggannya. Model komunikasi Stimulus Respon (S-R) merupakan perilaku (respon) manusia dapat diramalkan sesuai dengan stimulus yang akan dikirimkan. Mengenai hal tersebut maka dalam penelitian ini stimulus yang dimaksud adalah kualitas layanan (variabel X) dan respon yang dimaksud adalah loyalitas pelanggan (variabel Y), penelitian ini menggunakan metodelogi penelitian kuantitatif. objek penelitian ini adalah perusahaan SPBU 34-17123 Harapan Indah-Bekasi pelanggan yang lebih dari 3 kali mengisi Bahan Bakar Minyak (BBM) kendaraan roda empat sebagai subjek, serta kualitas layanan dan loyalitas pelanggan sebagai objek. Data yang diperoleh merupakan data primer dan data sekunder. Penelitian ini menggunakan sampel sebanyak 308 responden dari total penghitungan jumlah populasi sebanyak 1.342 pelanggan. Teknik sampling yang digunakan pada penelitian ini adalah non-probability sampling dengan metode accidental sampling. Penelitian ini menggunakan 5 uji instrument dengan menggunakan aplikasi
\end{abstract}


pengolahan data SPSS versi 24 (Statistical Package for the Social Science) yaitu uji validitas, uji reliabilitas, uji normalitas menggunakan grafik probability plot (p-plot), uji Anova (Analysis of variance) one way, analisis linier regeresi sederhana dengan menggunakan uji parsial serta dilakukan uji analisis regresi linier sederhana. Hasil dari penelitian ini adalah bahwa kualitas layanan di SPBU 34-17123 Harapan Indah-Bekasi mempengaruhi loyalitas pelanggan sebesar $57,9 \%$, dan $42,1 \%$ dipengaruhi oleh faktor-faktor lainnya. Hasil penelitian ini berpengaruh signifikan pada taraf signifikansi $0,05 \%$ dan pelanggan rata-rata setuju untuk loyal terhadap SPBU 34-17123 Harapan Indah-Bekasi.

Kata Kunci:Stimulus Respon, Kualitas Layanan, Loyalitas Pelanggan

\section{PENDAHULUAN}

Dewasa ini banyak perusahaan memanfaatkan peluang yang ada dalam melakukan suatu usaha berbisnis, seiring perkembangan jaman dan teknologi kebutuhan pelanggan pun kian beragam untuk dipenuhi. Saat ini kebutuhan pokok pelanggan tidak hanya meliputi tempat tinggal, makanan dan pakaian, tetapi kebutuhan pokok akan ketersediaan Bahan Bakar Minyak (BBM) menjadi kebutuhan pokok yang harus dipenuhi agar dapat menunjang segala aktifitas sehari-harinya. Menurut Direktorat Jendral Energi Baru dan Konservasi Energi (Dirjen EBTKE) Rida Mulyana menyatakan bahwa energi telah menjadi kebutuhan dasar (EBTKE, 2016). Mengenai hal tersebut maka saat ini begitu maraknya perusahaan-perusahaan penyedia BBM baik itu penyedia BBM sektor pemerintah maupun sektor swasta yang berlomba mengedepankan layanan yang lebih serta produk yang dihasilkan dengan kualitas yang baik dan dengan memberikan pelayanan yang terbaik bagi para pelanggannya.

PT Pertamina merupakan perusahaan pertambangan minyak dan gas yang telah bertransformasi menjadi perusahaan energi terkemuka di Indonesia, untuk lebih mengembangkan pelayanan dalam pendistribusian BBM dan memberikan kontribusi kepada pelanggan di Indonesia. PT Pertamina (Persero) yang merupakan Badan Usaha Milik Negara (BUMN) membentuk dua jenis kerjasama kemitraan dengan membuka usaha Stasiun Pengisian Bahan Bakar Umum (SPBU) bagi perusahaan-perusahaan swasta yang ingin bekerja sama dalam bentuk Company Owned Dealer Operated (CODO) dan Dealer Owned Dealer Operated (DODO) ("Info SPBU Pertamina”, 2015).
SPBU CODO Pertamina merupakan SPBU bentuk kerjasama antara PT Pertamina (Persero) dengan pihak-pihak tertentu, antara lain kerjasama pemanfaatan lahan milik perusahaan ataupun individu untuk di bangun SPBU Pertamina. Dealer Owned Dealer Operated (DODO) SPBU DODO merupakan SPBU bentuk kerja sama dimana lokasi dan investasi dilakukan seluruhnya oleh individu calon mitra, untuk mengembangkan outlet non Public Service Obligation (nonPSO) yang merupakan tidak adanya bantuan dari pemerintah terhadap margin antara harga pokok dengan harga jual. Pada saat ini SPBU DODO hanya menjual jenis produk Premium dan BBK (solar yang dijual adalah solar keekonomian) atau non subsidi ("info spbu pertamina, $2015 ")$

SPBU 34-17123 adalah SPBU DODO di lingkungan Harapan Indah-Bekasi yang merupakan sebuah lingkungan kehidupan urban "yaitu suatu daerah yang memiliki suasana kehidupan dan penghidupan moderen, dapat disebut daerah perkotaan" (Anshoriy \& Sudarsono, 2008, p. $88)$.

SPBU 34-17123 didirikan pada tahun 1999 merupakan SPBU pertama yang hadir di Harapan Indah, menjadi SPBU primadona yang hadir di Harapan Indah maka SPBU ini juga memiliki layanan untuk para pelanggannya misalnya memiliki lokasi strategis yang merupakan jalur utama Harapan Indah untuk menuju kearah Jakarta atau Cikampek. SPBU 34-17123 yang dimiliki oleh CV. Batavia Makmur buka pukul 05.30 WIB s/d 22.00 WIB ini dimiliki atas nama perorangan $\mathrm{Hj}$. Hasbiallah Ilyas, SPBU 34-17123 memiliki sarana yaitu 4 macam produk BBM serta prasarana adanya mitra tenant yang berada didalam 
Versi Online: https://journal.ubm.ac.id/index.php/business-management DOI : http://dx.doi.org/10.30813/bmj Hasil Penelitian

lingkungan SPBU ini dalam penunjang kegiatan penjualan BBM.

Tabel 1. Ketersedian BBM di SPBU 34-17123.

\begin{tabular}{llc}
\hline & & Mobil \\
\hline \multirow{2}{*}{ PerPertalite } & Liter & 12000 \\
\cline { 2 - 3 } & Jumlah Kendaraan & 1000 \\
\hline \multirow{2}{*}{ PerPertamax } & Liter & 4000 \\
\cline { 2 - 3 } & Jumlah Kendaraan & 267 \\
\hline \multirow{2}{*}{ PerPertamina Dex } & Liter & 500 \\
\cline { 2 - 3 } & Jumlah Kendaraan & 25 \\
\hline \multirow{2}{*}{ DexDexlite } & Liter & 1000 \\
\cline { 2 - 3 } & Jumlah Kendaraan & 50 \\
\hline
\end{tabular}

SueSumber: Supervisor SPBU 34-17123, 2018.

Berdasarkan data yang tersaji pada tabel.3 maka dapat diketahui pelanggan yang datang setiap harinya untuk melakukan pengisian BBM sebanyak 1.342 pelanggan dengan penjumlahan jumlah kendaraan dari seluruh produk BBM.

\section{KERANGKA TEORETIS \\ Stimulus-Respon}

Model stimulus-respon (S-R) adalah model komunikasi paling dasar.hubungan stimulus-respon Model ini menunjukkan komunikasi sebagai proses aksi-reaksi yang sangat sederhana. Stimulus respons bisa dalam bentuk positif maupun negatif. Secara implisit ada asumsi dalam model ini bahwa perilaku (respon) manusia dapat diramalkan sesuai dengan stimulus yang akan dikirimkan (Rustam \& Hakki, 2017, p. 101).

Stimulus Respon

Gambar 1. Model Stimulus Respon,Oleh Rustam dan Hakki 2017

\section{Kualitas Layanan}

Menurut Parasuraman, Zeithmal dan Berry (1990) menyatakan bahwa kualitas pelayanan merupakan penilaian atau sikap global berkenaan dengan superioritas suatu pelayanan (Sudarsono, 2016, p. 57 ).

Menurut Parasuraman dalam buku pemasaran jasa, disimpulkan bahwa terdapat limadimensi kualitas layanan (servqual) yaitu (Lupiyoadi dan Hamdani, 2008, p. 182) :
1. Berwujud (tangible), yaitu kemampuan suatu perusahaan dalam menunjukkan eksistensinya kepada pihak eksternal. Penampilan dan kemampuan sarana dan prasarana fisik perusahaan yang dapat diandalkan keadaan lingkungan sekitarnya merupakan bukti nyata dari pelayanan yang diberikan oleh pemberi jasa. Hal ini meliputi fasilitas fisik serperti gedung, gudang, dll. Dan perlengkapan peralatan yang digunakan (teknologi), serta penampilan pegawainya (p.182).

2. Keandalan (reliability), yaitu kemampuan perusahaan untuk memberikan pelayanan sesuai dengan yang dijanjikan secara akurat dan terpercaya. Kinerja harus sesuai dengan harapan pelanggan yang berarti ketepatan waktu, pelayanan yang sama untuk semua pelanggan tanpa kesalahan, sikap yang simpatik, dan dengan akurasi yang tinggi (p.182).

3. Ketanggapan (responsiveness), yaitu kebijakan untuk membantu dan memberikan pelayanan yang cepat (responsive) dan tepat kepada pelanggan, dengan penyampaian informasi yang jelas. Memberikan konsumen menunggu perserpsi yang negative dalam kualitas layanan (p.182).

4. Jaminan dan kepastian (assurance), yaitu pengetahuan, kesopanan santunan, dan kemampuan para pegawai perusahaan untuk menumbuhkan rasa percaya para pelanggan kepada perusahaan. Hal ini meliputi beberapa komponen antara lain komunikasi (communication), kredibilitas (credibility), keamanan (security), kompetensi (competence) dan sopan santun (courtesy) (p.182). 
5. Empati (emphaty), yaitu memberikan perhatian yang tulus dan bersifat individual atau pribadi yang diberikan kepada para pelanggan dengan berupaya memahami keinginan konsumen. Dimana suatu perusahaan diharapkan memiliki pengertian dan pengetahuan tentang pelanggan, memahami kebutuhan pelanggan secara spesifik, serta memiliki waktu pengoperasian yang nyaman bagi pelanggan (p.182).

\section{Loyalitas Pelanggan}

Menurut Oliver definisi loyalitas pelanggan adalah komitmen pelanggan bertahan secara mendalam untuk berlangganan kembali atau melakukan pembelian ulang produk atau jasa terpilih secara konsisten pada masa yang akan datang, meskipun pengaruh situasi dan usaha-usaha pemasaran mempunyai potensi untuk menyebabkan perubahan perilaku (Sudarsono, 2016, p. 85).

Menurut Tjiptono dalam Krisdayanti, loyalitas pelanggan dapat dilihat dari beberapa indikator, yaitu (Krisdayanti, 2017, p. 30-31).

\section{Pembelian berulang}

Pembelian ulang dapat merupakan hasil dominasi pasar oleh suatu perusahaan yang berhasil membuat produknya menjadi satu-satunya alternatif yang tersedia, namun selain itu pembelian ulang dapat pula merupakan hasil dari upaya promosi yang terus menerus dalam rangka memikat dan membujuk konsumen untuk membeli kembali merek atau produk yang sama (p.30).

2. Memberikan referensi kepada orang lain

Pelanggan yang loyal sangat potential untuk menyebarkan atau menjadi word of mouth advertiser bagi perusahaan (p.30).

3. Penolakan terhadap produk pesaing Konsumen yang setia terhadap suatu produk atau perusahaan tertentu cenderung terikat pada merek atau perusahaan tersebut dan akan kembali membeli produk yang sama lagi diperusahaan tersebut sekalipun tersedia banyak alternatif lainnya (p.30-31).

\section{Tahapan-Tahapan Loyalitas}

Menurut Oliver pada buku Lifestyle Marketing mengemukakan bahwa kepuasaan pelanggan dalam jangka panjang akan menciptakan loyalitas pelanggan, dan secara bertahap loyalitas dapat terbentuk sebagai berikut (Kartajaya, 2009, p. 60) :

1. Cognitive loyaltyyaituloyalitas pada level ini berdasarkan cognition semata, konsumen berdasarkan informasi yang diterima memperbandingkan produk/jasa yang satu dan lainnya dengan pemilihan keputusan pada informasi yang paling menarik bagi konsumen. Tingkat loyalitas pada tahap ini sangat labil dan konsumen sangat mudah berpindah (p.60).

2. Affective loyaltyyaitu loyalitas yang berdasarkan pada affect dan sangat bergantung pada tingkat kepuasan atau ketidakpuasan berdasarkan pengalaman konsumen menggunakan produk/jasa. Perlu menjadi catatan, tidak semua kepuasan konsumen menghasilkan loyalitas. Loyalitas pada tahap ini tahap ini lebih tinggi tingkatannya dibandingkan cognitive karena pengalaman yang terekam dalam benak konsumen (p.60).

3. Conative loyaltyyaitu konsumen menjadi berkomitmen karena percaya dan benar-benar berkeinginan membeli (intention) dan membeli kembali (repurchase) atau menjadi loyal (p.60).

4. Action loyaltyyaitupada tingkat ini intensitas pembelian konsumen menjadikan motivasi konsumen untuk secara terus-menerus membeli dan menjadi kebiasaan membeli produk/jasa (p.60). 
Hal yang menjadikan loyalitas dapat dipertahankan atau bahkan kehilangan loyalitas mungkin terjadi pada keempat tahap loyalitas (p.60).

\section{Hipotesis Penelitian}

Hipotesis penelitian/kerja merupakan anggapan dasar peneliti terhadap suatu masalah yang sedang dikaji. Dalam hipotesis ini peneliti menganggap benar hipotesisnya yang kemudian akan dibuktikan secara empiris melalui pengujian hipotesis dengan menggunakan data yang diperoleh selama melakukan penelitian. Misalnya: ada hubungan antara tingkat pengangguran dengan tingkat kriminalitas (Siregar, 2015, p. 38).

Ho: Tidak ada pengaruh kualitas layanan terhadap loyalitas pelanggan di SPBU 34-17123 Harapan Indah - Bekasi.

Ha: Ada pengaruh kualitas layanan terhadap loyalitas pelanggan di SPBU 34-17123 Harapan Indah - Bekasi.

\section{METODE PENELITIAN}

Peneliti menggunakan hubungan kausal untuk dapat mengetahui variabel yang mempengaruhi (independen) yaitu kualitas layanan dan variabel yang dipengaruhi (dependen) yaitu loyalitas pelanggan.

\section{Populasi Dan Sampel}

Penelitian ini menggunakan populasi yaitu pelanggan yang mengisi BBM di SPBU 34-17123 Harapan Indah-Bekasi. Pengambilan sampel menggunkaan rumus Slovin dengan hasil 1.342 sampel dengan teknik nonprobability sampling menggunakan metode accidental (sampel kebetulan). Dengan penghitungan sampel slovin sebagai berikut.

$$
\begin{array}{r}
\frac{n=\frac{N}{1+N e^{2}}}{1.342} \\
\frac{1+1.342(0,05)^{2}}{=} 308 \text { sampel }
\end{array}
$$

\section{Data Primer}

Dalam penelitian ini peneliti menggunakan data primer penelitian dengan menyebarkan kuesioner kepada responden penelitian.

\section{Data Sekunder}

Data sekunder mengenai perusahaan SPBU ini didapatkan dari supervisor SPBU 3417123 yang diberikan kepada peneliti.

\section{Teknik Analisis Data}

Analisis Regresi (Anareg) Sederhana

Bila suatu variabel tidak bebas (dependent variable) tergantung pada satu variable bebas (independent variable) maka hubungan antara kedua variabel disebut analisis regresi sederhana (Christianus, 2010, p. 135).

Penelitian ini menggunakan aplikasi SPPS 24 untuk memudahkan peneliti dalam pengolahan data.

\section{Skala Pengukuran}

Menggunakan skala angka 1 s/d 6 yaitu Agung Six Point Scale (ASPS) Problem Indicator karena (Agung, 2011, p.i).

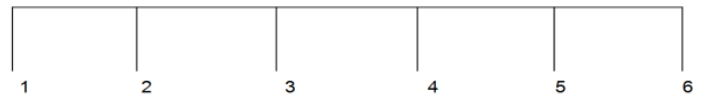

Gambar 2. Skala ASPS, Data Olahan Peneliti, 2018.

Dengan penjelasan sebagai berikut:
a. 1 : Menunjukkan sangat tidak setuju.
b. 2 : Menunjukkan tidak setuju.
c. 3 : Menunjukkan ragu-ragu d. 4 : Menunjukkan ragu-ragu mungkin setuju.
e. 5 : Menunjukkan setuju.
f. 6 : Menunjukkan sangat setuju.

\section{Uji Validitas}

Uji validitas, menurut Arikunto adalah suatu ukuran yang menunjukkan tingkat-tingkat keabsahan (validitas) suatu alat ukur.Suatu alat ukur yang valid mempunyai validitas yang tinggi, sebaliknya 
alat ukur yang kurang valid berarti memiliki tingkat validitas yang rendah (Rangkuti, 2008, p. 77).

\section{Uji Reliabilitas}

Reliabilitas adalah untuk mengetahui sejauh mana hasil pengukuran tetap konsisten, apabila dilakukan pengukuran dua kali atau lebih terhadap gejala yang sama dengan menggunakan alat ukur yang sama pula.

\section{Uji Normalitas P-PLOT}

Uji normalitas dengan normality plot sering digunakan untuk menguji secara informal apakah data berdistribusi normal atau tidak. Dengan menggunakan normality plot akan dengan mudah memahami karena berupa visual dibandingkan dengan pengujian lain yang menggunakan nilai-nilai tertentu dalam statistik (Sarwono, 2011, p. 239)

\section{Uji Normalitas Kolmogorov-Sminorv}

Sebagai alternatif untuk menguji kesesuian distribusi (goodness of fit), dapat digunakan uji kolmogorov-sminorv (Widandi \& Montarcih, 2017, p. 137). Apabila ukuran sampel $n>20$, gunakan rumus asimotik, untuk mendapatkan nilai Dcr. Apabila D < Dcr maka H0 (sampel yang memenuhi syarat distribusi diji) diterima (Widandi \& Montarcih, 2017, p. 139).

$$
\frac{1.36}{\sqrt{n}}
$$

\section{Uji Korelasi Bivariate}

Koefisien ini mengukur keeratan hubungan diantara hasil-hasil pengamatan dari populasi yang mempunyai dua varian (bivariate). Perhitungan ini mensyaraktkan bahwa populasi asal sampel mempunyai dua varian dan berdistribusi normal. Korelasi pearson banyak digunakam untuk mengukur korelasi data interval atau rasio (Santoso, 2009, p. 304).

\section{Uji ANOVA}

One Way ANOVA (ANOVA satu arah) adalah jenis uji parametrik untuk mengetahui perbedaaan rata-rata antara dua variabel

Angka korelasi diatas 0,5 menunjukkan korelasi cukup kuat, sedang dibawah 0,5 korelasi lemah(Santoso, 2009, p. 308).Jika data yang diperoleh mendapat nilai signifikansi < 0,05 maka dapat dikatakan bahwa ada perbedaan bermakna untuk tiap variabel dan sebaliknya jika nilai signifikansi > 0,05 maka diartikan tidak ada perbedaan yang bermakna antar variabel (Sani, 2018, p. 121).

\section{Lokasi dan Waktu Penelitian}

Penelitian ini berlokasi SPBU 3417123 Harapan Indah- Bekasi dan penelitian ini melakukan penyebaran kuesioner pada bulan Maret hingga Mei 2019.

\section{HASIL DAN PEMBAHASAN}

\section{Uji Validitas}

Pengujian validitas dalam penelitian ini menggunakan $\mathrm{n}=308$ responden dengan taraf signifikansi 5\% (0,05). Diperoleh $r$ tabel dengan rumus $(\mathrm{df}=\mathrm{n}-2)$ maka $(\mathrm{df}=308-2)=$ 306. Diperoleh $\mathrm{r}$ tabel sebesar 0,094. Dikatakan valid jika $r$ hitung $>r$ tabel, dan jika $r$ hitung $<\mathrm{r}$ tabel maka item tersebut tidak valid. Berdasarkan hasil perhitungan menggunakan SPSS maka didapatkanbahwa variabel kualitas layanan dan loyalitas pelanggan menunjukkan hasil signifika. Jadi dapat disimpulkan bahwa masing-masing indikator pernyataan adalah valid.

\section{Uji Reliabilitas}

Hasil uji reliabilitas variabel $\mathrm{X}$ adalah 0,919 dan variabel $\mathrm{Y}$ adalah 0,864 sehingga semua variabel dinyatakan reliabel.Tingkat reliabilitas untuk semua variabel adalah tinggi.

\section{Uji Normalitas P-PLOT}

Pengujian normalitas juga dapat didasarkan pada Normal Probability Plot. Pengujian data dinyatakan berdistribusi normal apabila titik-titik nilai data terletak 
kurang lebih dalam suatu garis lurus (Widyanto, 2013, p. 170).

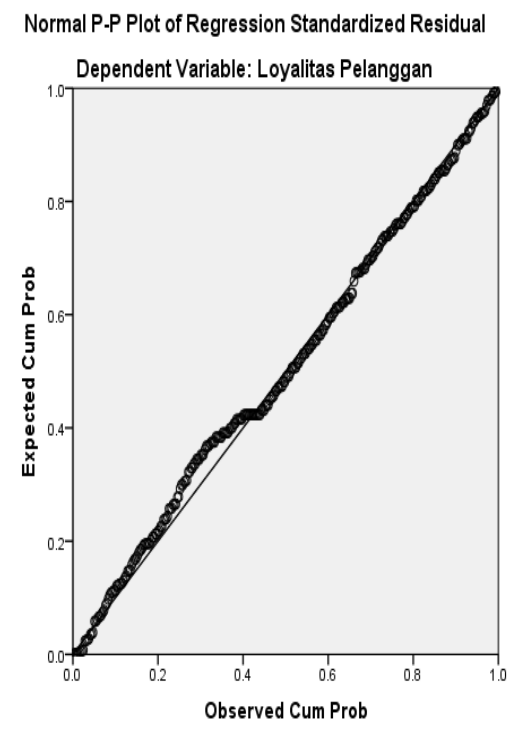

Gambar. 3 Grafik P-Plot.

Uji Normalitas Kolmogorov-Sminorv

Tabel. 2 Uji Kolmogor-Sminorv

\begin{tabular}{llr}
\hline \multicolumn{1}{c}{ One-Sample Kolmogorov-Smirnov Test } \\
\hline & \multicolumn{1}{c}{$\begin{array}{c}\text { Unstandard } \\
\text { ized } \\
\text { Residual }\end{array}$} \\
\hline $\mathrm{N}$ & Mean & 308 \\
\cline { 2 - 3 } $\begin{array}{l}\text { Normal } \\
\text { Parameters }{ }^{\text {a,b }}\end{array}$ & Std. & 4.0011086 \\
& Deviation & 6 \\
\hline Most Extreme & Absolute & .056 \\
\cline { 2 - 3 } Differences & Positive & .023 \\
\cline { 2 - 3 } & Negative & .056 \\
\hline Test Statistic & & $.022^{c}$ \\
\hline Asymp. Sig. (2-tailed) & \\
\hline a. Test distribution is Normal. & \\
\hline b. Calculated from data. & \\
\hline c. Lilliefors Significance Correction. & \\
\hline Sumber: Data Olahan Peneliti, 2019
\end{tabular}

Sumber: Data Olahan Peneliti, 2019

Pada hasil tabel 17 didapatkan bahwa nilai D < Dcr (D tabel) yaitu 0,056 < 0,077. Hasil 0,077 didapatkan dari penggunaan rumus asimtotik apabila $n>20$ sampel menurut (Widandi \& Montarcih, 2017, p. 139).

Berikut penghitungan rumus asimtotik pada taraf signifikansi $5 \%$.

$$
\begin{aligned}
\hline & \frac{1.36}{\sqrt{n}} \\
= & \frac{1.36}{17,5} \\
= & \frac{1.36}{308} \\
= & 0,077
\end{aligned}
$$

Maka dapat disimpulkan bahwa h0 diterima yang menunjukkan sampel memenuhi syarat distribusi yang diuji.

\section{Uji Korelasi Bivariate}

Berdasarkan perhitungan korelasi bivariate yaitu didapatkan hasil sebesar 0,761 yang menunjukkan bahwa hasil tersebut memiliki korelasi yang kuat karena diatas dari nilai 0,5 .

\section{Uji Anova}

Tabel 3. Uji ANOVA

\begin{tabular}{lrr|r|r|r|r}
\hline \multicolumn{8}{c}{ ANOVA } \\
\hline & $\begin{array}{l}\text { Sum of } \\
\text { Square }\end{array}$ & & & & \\
Model & \multicolumn{1}{c}{ M } & df & Square & F & Sig. \\
\hline 1 & Regre & 6748.9 & 1 & 6748.9 & 420. & .001 \\
ssion & 75 & & 75 & 204 & b \\
\hline Resid & 4914.7 & 306 & 16.061 & & \\
ual & 23 & & & & \\
\hline Total & 11663. & 307 & & & \\
& 698 & & & & \\
\hline
\end{tabular}

a. Dependent Variable: vary

b. Predictors: (Constant), varx

Dari tabel diatas dapat diinterprestasikan, nilai signifikan variabel adalah 0,001 . Apabila nilai signifikan $<0,05$ berarti Ho 
ditolak dan Ha diterima. Sebaliknya, jika nilai signifikansi $>0,05$, maka Ho diterima dan Ha ditolak. Dengan demikian dapat disimpulkan bahwa nilai signifikan variabel adalah $0,001<0,05$ maka dikatakan model persamaan regresi berdasarkan data penelitian adalah signifikan.

\section{Analisis Linier Regresi Sederhana}

Tabel diatas menampilkan nilai $\mathrm{R}$ yang merupakan simbol dan nilai koefisien korelasi. Nilai korelasi pada penelitian ini adalah 0,761. Nilai ini dapat diinterprestasikan bahwa hubungan kedua variable penelitian ini dikategori kuat. Tabel diatas juga menunjukkan nilai $\mathrm{R}$ square atau koefisien determinasi (KD) yang menunjukkan nilai $\mathrm{R}$ square adalah 0,579 menunjukkan bahwa variasi dari variabel $\mathrm{Y}$ (loyalitas pelanggan) dapat dijelaskan dengan variabel X (kualitas layanan) sebesar 57,9\% sedangkan $42,1 \%$ dijelaskan dengan faktorfaktor lain diluar model.

\section{PEMBAHASAN}

\section{Model Stimulus-Respon}

Model stimulus-respon (S-R) adalah model komunikasi paling dasar. model ini dipengaruhi disiplin psikologi. Model tersebut menggambarkan hubungan stimulusrespon. Model ini menunjukkan komunikasi sebagai proses aksi-reaksi yang sangat sederhana. Stimulus respons bisa dalam bentuk positif maupun negatif. Secara implisit ada asumsi dalam model ini bahwa perilaku (respon) manusia dapat diramalkan sesuai dengan stimulus yang akan dikirimkan (Rustam \& Hakki, 2017, p. 101).

\section{Kualitas Layanan}

Kualitas layanan menyatakan bahwa kualitas pelayanan merupakan penilaian atau sikap global berkenaan dengan superioritas suatu pelayanan (Sudarsono, 2016, p. 57 ).

\section{Loyalitas Pelanggan}

komitmen pelanggan bertahan secara mendalam untuk berlangganan kembali atau melakukan pembelian ulang produk atau jasa terpilih secara konsisten pada masa yang akan datang, meskipun pengaruh situasi dan usahausaha pemasaran mempunyai potensi untuk menyebabkan perubahan perilaku (Sudarsono, 2016, p. 85).

\section{SIMPULAN}

Berdasarkan penelitian yang telah dilakukan oleh peneliti pada bab-bab sebelumnya mengenai pengaruh kualitas layanan terhadap loyalitas pelanggan di SPBU 34-17123 Harapan Indah-Bekasi dapat ditarik kesimpulan sesuai dengan tujuan penelitian sebagai berikut :

1. Korelasi pada penelitian ini memiliki nilai 0,761 yang dapat dikatakakan bahwa penelitian ini memiliki hubungan yang kuat karena > 0,5 .

2. Hasil uji hipotesis parsial bahwa nilai t hitung $(20,499)$ $>\mathrm{t}$ tabel $(1,65)$ maka dikatakan variabel $\mathrm{X}$ berpengaruh signifikan terhadap variabel Y.

3. Nilai $\mathrm{R}$ square adalah 0,579 menunjukkan variabel $\mathrm{Y}$ (loyalitas pelanggan) dapat dijelaskan dengan variabel $\mathrm{X}$ (kualitas layanan) sebesar $57,9 \%$ sedangkan $\quad 42,1 \%$ dijelaskan dengan faktorfaktor lain.

4. Tahapan loyalitas pada penelitian ini adalah conative loyalty, bahwa konsumen menjadi berkomitmen karena percaya dan benar-benar berkeinginan membeli (intention) dan membeli kembali (repurchase) atau menjadi loyal.

\section{Saran}

1. Perlu adanya penelitian yang lebih 
mendalam mengenai kepercayaan dan kepuasan pelanggan di SPBU 3417123 Harapan Indah-Bekasi.

2. Disarankan untuk SPBU 34-17123 Harapan Indah Bekasi agar tetap meningkatkan kualitas pelayanan pelanggan, agar pelanggan lebih loyal.

3. Untuk SPBU 34-17123 agar selalu menjaga plang SPBU (Totem SPBU) agar dapat benar-benar terbaca dengan jelas bagi pelanggan, dikarenakan pada hasil kuesioner yang telah disebar bahwa pernyataan "Plang SPBU (Totem SPBU) dapat terbaca dengan mudah" memiliki nilai yang terendah dibandingkan pernyataan yang lainnya.

4. Untuk SPBU 34-17123 agar dapat mempertahankan pelayanan yang diberikan petugas untuk para pelanggan karena pada pernyataan "Pelayanan yang diterima pelanggan merupakan pelayanan yang baik" memiliki nilai tertinggi dibandingkan dengan pernyataan lainnya.

\section{DAFTAR PUSTAKA}

EBTKE. (2016). Energi Telah Menjadi Kebutuhan Dasar. Diperoleh November 10,2018,

dari

http://ebtke.esdm.go.id/post/2016/05/23/

1240/dirjen.ebtke.energi.telah.menjadi.ke butuhan.dasar

Christianus. (2010). Seri Belajar Kilat SPSS 17. Yogyakarta: Andi Yogyakarta ELCOM.

Info SPBU Pertamina. (2015). Spbu. Diperoleh Oktober 10, 2018, dari spbu.pertamina.com: www.spbu.pertamina.com

Kartajaya, H. (2009). Lifestyle Marketing, Servlist: Paradigma baru Pemasaran bisnis jasa dan lifestyle. Jakarta: Gramedia Pustaka Utama.

Krisdayanti, H. (2017). eprints. Diperoleh Februari 1, 2019, dari radenfatah.ac.id:http://eprints.radenfata h.ac.id/958/1/Helisia\%20Krisdayanti\%2 0\%2813190112\%29.pdf.
Lupiyoadi, R., \& Hamdani, A. (2008). Manajemen Pemasaran Jasa. Jakarta: Salemba Empat.

Sani K, F. (2018). Metodoogi Penelitian Farmasi dan Komunitas Eksperimental. Yogyakarta: Deepublish.

Rangkuti. (2008). The Power Of Brands Teknik Mengelola Barand Equity dan Strategi Pembangan Merek + Analisis Kasus dengan SPSS. Jakarta: PT Gramedia Pustaka Utama.

Rustam, A. S., \& Hakki, N. (2017). Pengantar ilmu komunikasi. Sleman: Deepublish.

Santoso, S. (2009). Panduan Lengkap Menguasai Statistik dengan SPSS 17. Jakarta: PT. Elex Media Komputindo.

Sarwono, J. (2011). Buku Pintar IBM SPSS STATISTIK 19 Cara Operasi, Prosedur Analisis data, dan Interprestasi. Jakarta: PT Elex Media Komputindo.

Sudarsono, A. (2016). Manajemen Pemasaran Jasa Perhotelan. Yogyakarta: Deepublish Publisher.

Widandi, \& Montarcih, L. (2017). Rekayasa Statistik Untuk Teknik Pengairan. Malang: UB Press.

Widyanto, M. A. (2013). Statistika Terapan: Konsep dan Aplikasi SPSS dalam penelitian Bidang Pendidikan,Psikologi dan ilmu sosial lainnya. Jakarta: PT Elex Media Komputindo. 